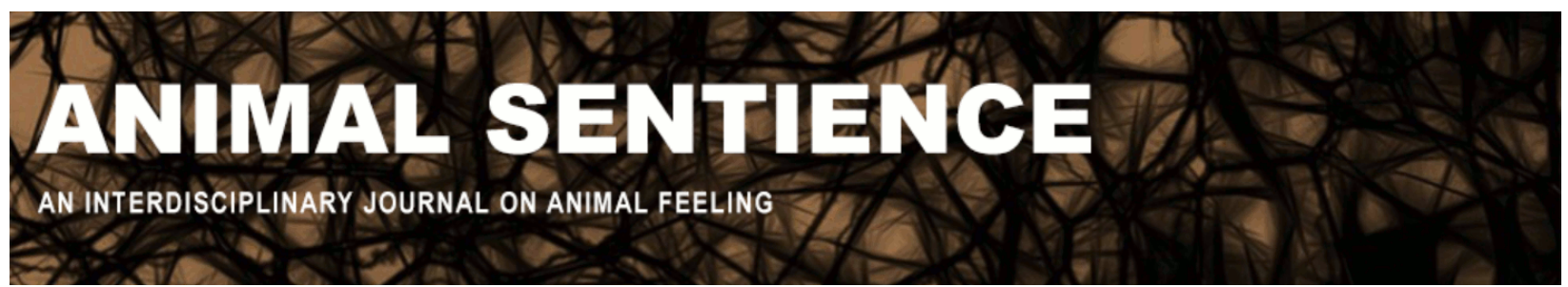

Sözmen, Beril (2016) Inalienable rights and pluralism in animal advocacy. Animal Sentience 7(16)

DOI: $10.51291 / 2377-7478.1117$

Date of submission: 2016-06-27

Date of acceptance: 2016-07-06

(c)

This article has appeared in the journal Animal

Sentience, a peer-reviewed journal on animal

cognition and feeling. It has been made open access,

free for all, by WellBeing International and deposited

in the WBI Studies Repository. For more information,

please contact

wbisr-info@wellbeingintl.org.

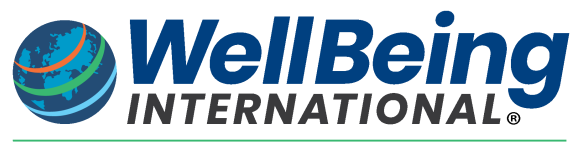

SOLUTIONS FOR PEOPLE, ANIMALS AND ENVIRONMENT 


\title{
Inalienable rights and pluralism in animal advocacy
}

Commentary on $\mathrm{Ng}$ on Animal Suffering

\author{
Beril İdemen Sözmen \\ Istanbul Technical University \\ Department of Humanities and Social Sciences, Istanbul
}

\begin{abstract}
I comment on two of Ng's suggestions. There is a lack of support for his suggestion that some experiments on individual animals will be useful for future success, so they should be permitted. I also question his recommendation that animal advocacy should focus on farmed animals first and wild animals later. The lack of solid support for why this would be a more effective strategy leads me to suggest a more pluralistic support of a variety of types of advocacy.
\end{abstract}

Keywords: wild animal suffering, farmed animals, advocacy, pluralism, experiments on animals

Beril Idemen Sözmen teaches
philosophy at the Technical
University of Istanbul. Her main
research is in the field of normative
ethics and theories of selfhood.
http://akademi.itu.edu.tr/sozmenb/

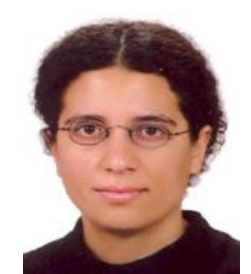

I want to respond to two of $\mathrm{Ng}^{\prime} \mathrm{s}$ (2016) suggestions on how to increase the influence of animal welfare advocates: Allowing (some) experiments on other animals and prioritising advocacy on farmed animals over advocacy on wild animals.

The first suggestion is Ng's call for caution "in pressing for the curtailment of animal research that can increase our scientific knowledge in the interests of human or animal welfare" (7). There is a warning because in the long run animals, both human and non-human, are likely to be harmed by the resulting lack of scientific progress. This seems true, but it disregards the most fundamental interests of the individuals that are experimented upon. Humans and other animals are comparable in that they have an interest in their lives and liberty; these are valuable because the individual organism in question values them. Humans and other animals are also sufficiently comparable in their capacity to communicate their likes and dislikes as well as their agreement or disagreement about how they are treated. In the human case, we rightly demand freely given, informed consent by the participant in research. A similar respect for the individual should also be the guiding principle in our dealings with other animals. If not, we need an argument as to why utilitarian considerations trump individual rights in one case but not the other. $\mathrm{Ng}$ does not provide support for his suggestion other than the unquestionable need for more progress in fields related to animal welfare.

Further support is also required for Ng's next suggestion that we should direct our resources for advocacy to reduce the suffering of farmed animals first because we need more scientific research on animal cognition and animal welfare as well as ecological risks when it comes to 
animals in the wild, and because human responsibility for the existence and suffering of farmed animals is more likely to be accepted. We need this acceptance in order to prepare the field for the future. Intervention in the wild for the sake of suffering animals has indeed been used to ridicule the concern for the suffering of other animals. It is also reasonable to assume that animal advocates have limited resources and that these should be invested wisely and profitably, giving priority to what is more effective.

Nevertheless $\mathrm{Ng}^{\prime}$ s suggestion is based on an assumption and ought to be better supported. The suggestion that creating more awareness about and interest in reducing suffering in the wild would support public sensibilities about the suffering of farmed animals seems just as reasonable and likely. Considering how much effort individuals and communities have put into being prepared and investing in assisting other animals in their vicinities, whether they are birds or hedgehogs, stray dogs or cats, deer or bears, it seems premature to neglect any type of interaction without solid data to back one type of advocacy over the other.

Relations between humans and other animals are very diverse. While our history of domesticating animals gives us some additional reasons to work on behalf of farmed animals, this need not lead to a prioritisation of one advocacy over the other. While many communities, both urban and rural, have more and stronger relationships with farmed animals, human-animal relationships in the wild are a valuable resource for gaining more information on animal lives, interests, and the possibilities of effective interventions that reduce suffering. The debate around what sort of advocacy to support should therefore take into account the variety of human-animal relationships and be more pluralistic and creative. Related to this point is another consideration: Not only the relationships between humans and other animals but also the interests, moral sensibilities and dedication of animal advocates show great variety. In the long run, it might well be more effective to support pluralism in animal advocacy. This would not only be useful for generating new ideas, approaches and moral concerns but it would also allow potential future advocates to find areas better suited to their individual skills, thus making them more effective. It would also enable us to make better-informed decisions in the future based on the data that diverse advocacy traditions will supply.

Ng makes some excellent points: Acceptance and public opinion are fundamental concerns, even if they are concerns for no other reason than our limited ability to act independently of them. It is also true that in spite of advances in our knowledge about animal cognition and methods of reducing suffering, the improvements in welfare are insufficient. While I do not believe that our need for more knowledge justifies treating any individual animal as merely an object of research, animal advocacy is required to develop and to support alternative methods of research. $\mathrm{Ng}$ is also undoubtedly right in his emphasis on the need to prioritise and use our resources as effectively as possible. While the methods he suggests are indeed simple and commonsensical, I would urge more variety and pluralism in animal advocacy, assigning priorities only when they are supported by reliable studies on efficiency and on the dynamics of public opinion. The suffering in the wild is of such immense proportion that any neglect today seems inexcusable; it is too important an issue to rest satisfied with our unexamined, commonsense assumptions. The scale of the problem is reason enough not to assign priorities a priori. 


\section{References}

$\mathrm{Ng}$, Y-K. (2016). How welfare biology and commonsense may help to reduce animal suffering. Animal Sentience 2016.007. 